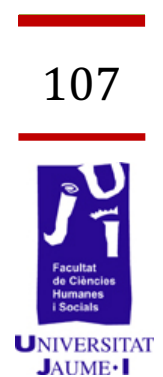

\title{
Iconografía de Santa Catalina de Alejandría en la pintura valenciana del siglo XV
}


El siglo XV en el Reino de Valencia, también, es considerado como el «Siglo de Oro» del arte valenciano. Esto se debe a la variedad de corrientes artísticas que tuvieron lugar durante este periodo. En un ambiente de conflictos bélicos y cambios dinásticos el arte se ve financiado por las personalidades más influyentes del reino. La llegada de pintores de diversas partes de Europa hará que en las diferentes obras se aprecien cambios considerables dependiendo de la corriente artística de la cual se inspira el pintor. En este clima se encuentra la representación de Santa Catalina de Alejandría, una mártir legendaria, cuya vida en defensa del cristianismo sirvió de modelo de conducta a la Iglesia Católica. En el trabajo se intentará mostrar como a pesar de las diferentes corrientes artísticas a las que pertenecen las obras seleccionadas, los atributos no varían. Así mismo se destacará la iconografía más representativa de la Santa y se comparará con la de algunas otras santas mártires que fueron pintadas en el mismo contexto histórico y artístico que Santa Catalina de Alejandría y que murieron decapitadas igual que ella.

Palabras clave: pintura, iconografía, martirio, Santa Catalina de Alejandría, Reino de Valencia.

\section{Introducción}

El Reino de Valencia durante el siglo XV concentra una gran producción artística, de ahí que este considerado como el "Siglo de Oro" del arte valenciano. Esta faceta artística no engloba exclusivamente a la pintura, sino que se trata de un periodo en el que las artes se ven financiadas por las elites sociales. Aunque este período de esplendor no se refleja en el ámbito político, ya que nos encontramos en un panorama belicoso y con problemas dinástico, sobre todo, en la primera mitad del siglo. Los enfrentamientos con la Corona de Castilla son constantes y no mejoran las relaciones tras instaurarse un rey castellano en la Corona de Aragón. A estos enfrentamientos cabe sumarle el de los territorios italianos, firmes luchas por la conquista del Reino de Nápoles (Furió, 2001).

Los estudios realizados a lo largo de la historia sobre Santa Catalina de Alejandría han sido variados, normalmente centrándose en la historia de la santa o en alguna obra en especial, todos estos proyectos tienen que tener en cuenta un libro fundamental para la realización de trabajos sobre mártires, con ello nos referimos a La Leyenda Dorada de Santiago de la Vorágine, un libro escrito en el siglo XIII que recoge la vida de los santos y santas de la cristiandad.

La Luz de las Imágenes, es una fundación de la Comunidad Valenciana que se encarga de restaurar el patrimonio artístico valenciano. Durante más de diez años han realizado exposiciones con las obras restauradas, dejando ver la gran belleza del patrimonio de esta comunidad. En estas exposiciones (Valencia, Orihuela, Segorbe...) se ha podido comprobar la 
gran cantidad de obras religiosas que hay dedicadas a santas mártires, entre ellas Santa Catalina de Alejandría.

Los trabajos realizados hasta el momento en los que la figura de Santa Catalina aparece comentada son los diccionarios iconográficos, en general o los que se centran exclusivamente en la figura de los santos, de todos ellos el más importante es el escrito por Louis Reau (1955-1958). Los últimos estudios realizados sobre este tema, los encontramos en los artículos de Vicent F. Zuriaga Senent (2012), El dolor como triunfo. Sacrificio, tortura y liberación en las mártires cristianas o el de Irene González Hernando (2012), Santa Catalina de Alejandría.

Como se puede apreciar el estudio de Santa Catalina de Alejandría en el contexto en el cual se centra el trabajo no ha sido investigado como tal, dada la cantidad de obras en las que aparece representada la santa creo conveniente e interesante la realización de dicho trabajo.

\section{Objetivos}

El presente trabajo tiene como objetivo hacer un análisis iconográfico de la figura de Santa Catalina de Alejandría en la pintura del Reino de Valencia durante el siglo XV. Contextualizarla, es decir, hablar de su historia, del período en el que se desarrolló su leyenda y como acabó siendo venerada en la Comunidad Valenciana. A través de las diferentes imágenes encontradas de Santa Catalina de Alejandría, ver las variantes del gótico que surgieron en el siglo XV (gótico internacional, la influencia flamenca, la italiana...) y analizar como afectaron a la representación de la santa, en su aspecto iconográfico.

\section{Material y método}

El presente artículo surge de la busqueda bibliografíca que se realizó para la elaboración de un Trabajo de Fin de Grado. El proyecto surguió a raíz de la observación de diferentes retablos de mártires, de los cuales la figura de Santa Catalina de Alejandría aparecía en varios de ellos. Tras dicha observación, se pasó a analizar las obras siguiendo el método iconográficoiconológico, método que se centra en el estudio de las imágenes, su origen y evolución. Para la comprensión de éste partimos de la teoría del símbolo de Hegel y de la concepción de que el hombre vive en un mundo simbólico de Cassirer (Checa, 1980). 


\subsection{Santa Catalina de Alejandría: vida, martirio y leyenda}

O Katherina, tyrannum superans, Doctos docens et rotas lacerans.

(REAU, 1955-1958: 265)

La vida de Santa Catalina de Alejandría es totalmente legendaria y se encuentra narrada por primera vez en el Menologio de Basilio, aunque será popularizada en Occidente por Santiago de la Voragine en el libro la Leyenda Dorada, escrito en el siglo XIII, recoge la vida y sacrificios de los primeros mártires de la cristiandad. Santa Catalina era la hija del rey Costo, una joven que había sido introducida en las artes liberales, consiguiendo dominarlas. Cierto día el emperador ordenó realizar sacrificios rituales a los ídolos, al enterarse de la noticia Catalina se presentó ante él para apelar por el desatino que estaba cometiendo. Ambos mantuvieron una conversación en la que Catalina le expuso porque ella veneraba a otro dios. Ante la firmeza de los argumentos de la joven el emperador no supo defenderse, por ello llamó a los mejores filósofos del Imperio para que revocaran las argumentaciones de la muchacha. De esta forma Santa Catalina tuvo que enfrentarse a los cincuenta filósofos, que no supieron revocar sus argumentos y acabaron convirtiéndose al cristianismo; el emperador, al enterarse, ordenó quemar a los filósofos. Tras esto le propuso a Catalina que se fuera a vivir con él al palacio, petición que la joven declinó. Tras la negativa, ordena que se azote a Santa Catalina con látigos de hierro compuestos de garfios afilados. Por diversos motivos, el emperador se ve obligado a abandonar por unos días la ciudad y deja a Catalina encerrada en las mazmorras donde es visitada por la emperatriz y Porfirio, general de la guardia, tras hablar con la prisionera, ambos con otros doscientos soldados, se convierten al cristianismo. Cuando el emperador regresó vio que la joven estaba más hermosa que nunca y creyó que los soldados no habían obedecido las órdenes que dictó, por eso mandó castigarlos; al enterarse de lo sucedido Santa Catalina salió en defensa de ellos y dijo que era Dios quien la había alimentado. Tras volver a proponerle el emperador que viviera en palacio y ella negarse, éste ordeno torturarla con unas ruedas dentadas. En dicho momento las ruedas se rompieron y mataron a una serie de paganos. Tras esto la emperatriz salió en defensa de la joven y por ello fue decapitada al igual que Porfirio y los doscientos soldados. Finalmente, el emperador ordena la decapitación de Santa Catalina, pero antes ello, ella oyó una voz que le decía «iven amada mía, esposa mía, ven!» (Vorágine 1982: 772), después de la decapitación, su cuerpo fue sepultado en el monte Sinaí. "Cinco cosas especialmente dignas de admiración caracterizaron a esta santa: su sabiduría, su elocuencia, su fortaleza, su purísima castidad y los muchos privilegios con que Dios quiso honrarla » (Vorágine 1982: 772).

En el siglo XV surge la iconografía de los desposorios místicos tras una traducción realizada por $\mathrm{F}$. Jean de Bungay en 1438 y que no constaba en la primera redacción del libro realizada por Santiago de la Voragine. Reau 
(1955-1958) cree que esta escena se debe a una interpretación literal que debió hacer Bungay de las palabras dichas por Santa Catalina «qu'elle était fiancée au Christ» (Reau, 1955-1958: 263) junto con la confusión que pudo producir la representación de la rueda, ya que en ocasiones era tan pequeña que podría parecer un anillo. Esta escena adquirirá gran importancia en el siglo XV y XVI, sobre todo, después del Concilio de Trento cuando se impone la ley de la dulcificación a la hora de representar el martirio.

Este relato, que no aparece en ningún texto de la antigüedad cristiana, se extendió a partir del siglo IX adquiriendo importancia dentro del rito católico y nos ha dejado cuadros y retablos tan fascinantes e interesantes como los que se expondrán a continuación.

\subsection{El martirio cristiano: sentido y significado}

El término martyr proviene del griego y significa testigo. Para poder comprender lo que significa el martirio para el cristianismo hay que entender primero el concepto de redención, expresado por Cristo a través de su muerte en la cruz; al dar su vida para salvar a la humanidad sirvió de ejemplo a los mártires. Éstos, llevan «hasta las últimas consecuencias la afirmación del testimonio en la fe en Cristo» (Zuriaga, 2012:158).

Una persona se convierte en mártir tras haber sufrido un gran tormento, San Agustín de Hipona en sus Sermones sobre los mártires, en más de una ocasión repite la frase «no es la pena, sino la causa, lo que hace a los mártires de Dios» (AAVV, 1984: 110-111). Con esto nos está queriendo decir que hay muchas personas que sufren una gran agonía en la vida, pero no todas acaban convirtiéndose en mártires, sino que para ser un mártir lo importante es la causa de ese sufrimiento, pues sabían que Dios en el momento del juicio no les iba a preguntar cuanto habían sufrido sino porqué lo habían hecho. Ellos lucharon contra el pecado hasta que su sangre fue derramada, pues sabían que la vida terrenal era efímera y lo que importaba era la vida eterna, Dios les había hablado y ellos debían seguir sus órdenes, ya que el tormento era el último paso para alcanzar la felicidad.

En el cristianismo el martirio es entendido como una victoria en la que la vida eterna ha triunfado sobre la muerte. Para comprender el concepto de la vida eterna se ha de tener un sentimiento de fe, hay que entender, como dice San Agustín de Hipona, que el alma y el cuerpo son dos cosas diferentes y que mientras el cuerpo muere, el alma permanece inmortal viviendo en el paraíso.

Cuando los mártires sufren los tormentos, ponen todas sus esperanzas en Dios, ya que él fue el primero en sufrir, les mostro el camino, un camino doloroso que los lleva a morir por la verdad, pero que a su vez los lleva a la vida eterna, una vida donde entrán coronados por el sacrificio que han realizado, pues han sabido resistir las tentaciones de la vida terrenal y ahora en la eterna son glorificados. El papel que desempeñaron los 
mártires en la Iglesia fue muy importante ya que sirvieron como ejemplo de modelos de conducta de un buen cristiano.

\subsection{Estudio iconográfico de Santa Catalina de Alejandría}

La representación de Santa Catalina de Alejandría en la pintura valenciana del siglo XV se podría decir que es bastante frecuente, muestra de ello son los retablos y tablas que se van a analizar a continuación. En ellos se podrán apreciar las dos corrientes fundamentales del gótico que predominan en este siglo: el estilo internacional y el flamenco. A los cuales sustituirá a finales de siglo y, sobre todo, en el XVI el renacimiento italiano. Cabe centrarse en el objetivo de este trabajo que es la representación iconográfica de la santa, es decir, en cuáles serán los principales atributos que predominaran en el periodo que concierne al trabajo.

a) Atributos:

Los mártires de la cristiandad se representan con una serie de elementos que Panofsky denominó atributos. Estos atributos hacen referencia a momentos de la vida de los mártires, en la mayoría de ocasiones al tormento que sufrieron.

El caso de Santa Catalina de Alejandría no es diferente al de los otros mártires, de ahí que sus atributos sean los siguientes: la rueda, atributo del suplicio, en ocasiones es representada completa y a veces un trozo de ella.

«De aquí a tres días podremos tener preparadas cuatro ruedas cuajadas de agudísimos clavos y de pequeñas sierras dentadas. Será un instrumento de tortura verdaderamente horroroso; si lo aplicamos a esta doncella su cuerpo en poco rato quedará acribillado y hecho trizas por los pinchazos de los garfios y por las sajaduras de las sierras» (Vorágine, 1982: 770).

Hay ocasiones en las cuales las ruedas son representadas en el momento en que el ángel las rompió, como sucede en la tabla del siglo XIV de Pseudo- Jacopino, El martirio de Santa Catalina, que hoy en día se encuentra en el Raleigh North Carolina Museum of Art.

«Cuando el artefacto comenzó a girar a vertiginosa velocidad, un ángel hizo saltar las ruedas con tal fuerza que al dispersarse sus fragmentos en diversas direcciones y chocar violentamente contra los espectadores, mató a cuatro mil de ellos, todos los cuales eran paganos» (Vorágine, 1982: 770).

La espada de la decapitación, la única forma en la que consiguieron poner fin a su vida. La palma símbolo del martirio, un atributo no exclusivo de Santa Catalina ya que indica que todo aquel que esté representado con ella fue martirizado. La corona que hace alusión a su linaje real. El libro referencia a la sabiduría de la santa, a la ciencia: «entregada desde su niñez al estudio de las artes liberales, adquirió muy extensos y profundos conocimientos en la materia de estas disciplinas» (Vorágine, 1982: 766). Y en ocasiones con la cabeza del emperador coronada bajo sus pies, el hombre que la persiguió y que ordenó su decapitación.

b) Formas de representación: 
Varias son las formas de representación de Santa Catalina de Alejandría en la pintura del siglo XV valenciano. Por un lado, la podemos encontrar como figura aislada, en esta ocasión suele representarse como una joven bella, una princesa real, portando alguno de sus atributos representativos. La ropa con la que se le representa suele hacer alusión a la alta alcurnia de la joven y varía dependiendo de la moda imperante del momento. Por otro lado, está la representación dentro de un retablo en la que la aparición de la santa se tiende a dar de diversas formas. La podemos encontrar dentro de un retablo que narre su leyenda, en él suele aparecer en la tabla central un retrato de la joven y en las tablas laterales (normalmente de unas dimensiones inferiores) diversas tablas que narran los momentos de su martirio, entre las escenas más destacadas encontramos: el momento en el que va a ser torturada con las ruedas dentadas, la decapitación y el debate con los filósofos. Aunque estas son las escenas más representadas no son las únicas, dependiendo del encargo y de lo que se quiera relatar hay más pasajes de su vida o menos. Finalmente, es una santa que la podemos encontrar en muchas de las predelas de los retablos, esto se debe a que es una de las Quatuor Virgines Capitales junto con Santa Bárbara, Santa Dorotea y Santa Margarita (Giorgi, 2005).

Como hemos comentado, la mayoría de obras de arte que nos han llegado hasta nuestros días sobre la imagen de Santa Catalina de Alejandría en la pintura valenciana del siglo XV, son retablos o tablas, que probablemente formaron parte de uno. El arte de la retablística fue introducido en el Reino de Valencia por los catalanes y aragoneses desde la fundación del Reino en el siglo XIII convirtiéndose en el XV en la «magia y exquisitez del lirismo con que operan los mejores maestros del Gótico Internacional» (Company, 2006: 8). Es prácticamente imposible contar todos los contratos que se realizaron en este periodo sobre retablos, dada la gran cantidad que se han perdido. Fue el periodo dorado de la retablistica, que se alargó hasta la primera mitad del siglo XVI. La segunda mitad del siglo XV y la primera del XVI destacan por su monumentalidad. Durante el paso del gótico al renacimiento se supieron adaptar muy bien las formas modernas con las antiguas, y gracias a ello encontramos retablos con un diseño gótico y pinturas de estilo renacentista; llegando a conseguir grandes obras de arte que no dejaban ni dejan indiferente a la mirada del espectador.

Análisis de las obras:

La figura de Santa Catalina de Alejandría fue representada por todo el Reino de Valencia durante el periodo que estamos tratando, muestra de ello son los bellos retablos y cuadros que han llegado hasta nuestros días. 
En la provincia de Castellón, concretamente en el pueblo de Albocácer, se encuentra uno de los compartimentos del retablo de la Virgen de la Esperanza, en concreto, el de la Visión Mística de San Bernardo y el Calvario realizado por Jaume Mateu y Antón Peris entre 1412 y 1420 aproximadamente (Fig. 1). De las diferentes escenas que nos muestra el retablo, destaca la central, por su posición y tamaño. En ella se representa a la Virgen de la Esperanza rodeada de ángeles. Esta tabla queda cercada por varias escenas más, en un lado, está representada la figura de san Bernardo y al otro, la de Santa Bárbara con sus atributos más característicos, la torre con tres ventanas y la palma del martirio. Sobre ella, se representa a Santa Águeda sentada en un trono, portando en sus manos los atributos de la joven, la palma del martirio y unos pechos sobre una bandeja. Sobre San Bernardo, localizamos a Santa Catalina, en la misma posición en la que Santa Águeda está representada, al igual que la otra santa también posa con la palma del martirio y con uno de sus atributos característicos, la rueda dentada, representada en su totalidad y de gran tamaño. Coronado el conjunto la Crucifixión. En el conjunto del retablo se aprecia la influencia arraigada del gótico.

La obra de Antoni Peris la encontramos también en el sur del Reino de Valencia, esta vez junto al Maestro de Ollería. En la Iglesia Arciprestal de la Asunción de Pego, Alicante, se encuentra un magnífico retablo de la Virgen de la Esperanza, realizado en la primera mitad del siglo XV (Fig.2). La obra presenta similitudes con el retablo tratado con anterioridad, dado que la imagen central es la de la Virgen de la Esperanza y está representada de una forma muy parecida a la anterior, pues la Virgen está entronizada y rodeada de ángeles, a pesar de la variación del número de estos, la actitud de la Virgen es muy similar. A ambos lados de ésta, se encuentran representados Santa Catalina y San Bartolomé Apóstol portando sus dos atributos, el libro y el cuchillo. Sobre ellos dos las escenas de su martirio. En la parte superior encontramos de derecha a izquierda: la Anunciación, el entierro de la Virgen y el nacimiento de cristo. Y coronando el conjunto, al igual que en el retablo anterior, la Crucifixión.

Pasando a analizar las tablas relevantes del retablo para el trabajo, analizaremos en primer lugar, la que representa el martirio de Santa Catalina. En el centro de la imagen, se encuentra Santa Catalina arrodillada y con la parte superior del cuerpo descubierta, quedando sus senos cubiertos por sus brazos colocados en posición orante. Frente a ella, se halla la rueda dentada, la cual están intentado poner en funcionamiento dos soldados. Estos atentos a las palabras que la joven les está diciendo no se dan cuenta de que dos arcángeles con espadas están golpeando las ruedas, saltando los pedazos de éstas al público expectante. Detrás de Santa Catalina y elevado sobre un pequeño podio se encuentra el emperador atento a la escena que se está viviendo ante él. En la tabla inferior se localiza una representación de Santa Catalina como si fuera un retrato. La joven de pie y un poco inclinada aparece coronada. En la mano izquierda porta la palma del martirio mientras sujeta la rueda dentada representada en su totalidad. Sin embargo, en la mano derecha sujeta la 
espada de la decapitación. Si seguimos el filo de ésta nos damos cuenta que la espada descansa sobre la boca abierta del emperador, que es representado a los pies de la joven, tumbado boca arriba, mostrando como la fe ha vencido contra la herejía y el pecado.

Joan Reixach (Reino de Valencia?, h. 1411- 1485/90) fue uno de los artistas que nos dejó para la posteridad uno de los grandes y bellos retablos del momento. El Retablo de Santa Catalina Mártir que hoy podemos encontrar en la Iglesia Parroquial de Villahermosa del Río, Castellón, está datado en 1448 y nos muestra la influencia del Gótico Internacional de Gonzal Peris (Fig. 3). Nos encontramos ante un retablo, formado por seis tablas y una predela. Las dos tablas laterales muestran los momentos más relevantes de la vida de la santa y la tabla central está dividida en tres escenas: las dos superiores que representan pasajes de la vida de Cristo (el nacimiento y la crucifixión) y la parte inferior que representa la santa como si fuera un retrato.

De izquierda a derecha, encontramos dos tablas: la superior muestra los Desposorios de Santa Catalina, en dicha escena se representa a la Virgen entronizada con el Niño Jesús en su regazo, frente a ellos Santa Catalina está arrodillada recibiendo el anillo de desposada de la mano del Niño Jesús. Rodeando a las tres figuras principales, de esta tabla, se hallan cuatro ángeles. La tabla inferior muestra dos escenas, por un lado, a Santa Catalina ante el rey y por el otro, a Santa Catalina con los filósofos. En la primera escena, apreciamos en la parte central al rey entronizado, vestido con ropajes orientales y llevando una corona. Frente a él se encuentra Catalina serena e imperturbable ante su presencia. Completan la escena ocho personajes de diferente rango y oficio que podemos diferenciar gracias a sus vestiduras. En la escena inferior, se representa al rey también entronizado pero está vez en un lateral, mientras que es la figura de Santa Catalina la que se encuentra en el centro de la tabla, con las manos en movimiento. Alrededor de ellos apreciamos ocho personas y un soldado. Estas dos escenas podrían confundirse dado que están representadas de forma muy similar y con el mismo número de personajes. Se ha determinado que estos dos pasajes están en este orden y no a la inversa por dos motivos: por un lado, porque si nos fijamos en el conjunto del retablo tiene más lógica ya que las imágenes están distribuidas en el orden que Santiago de la Vorágine nos las relata en su obra, a excepción de las dos escenas que muestran las imágenes de la vida de Cristo y la introducción de los desposorios místicos. Y en segundo lugar, porque en el acto superior es el rey quien adquiere importancia al estar situado en el centro de la tabla, representación lógica en la escena en que Santa Catalina se presenta ante el rey, ya que nos está mostrando al personaje. Sin embargo, en la otra escena es Catalina quien está en el centro, en actitud explicativa, como si estuviera dando un discurso: sus argumentaciones ante los filósofos.

En la tabla central, encontramos en la parte superior las dos escenas que representan la vida de Cristo, que no pasaré a comentar dado que son irrelevantes para el presente trabajo. La tabla inferior, la que tiene las 
dimensiones más importantes del conjunto, nos presenta a la santa como si fuera un retrato, con una orante a sus pies. Santa Catalina está representada como princesa real, muestra de ello es la corona que lleva sobre la cabeza. Ambas manos las muestra ocupadas con dos de sus atributos, la rueda del suplicio, en este caso está representada de forma parcial, como si fuera uno de los trozos que quedó después de que el ángel la rompiera y en la otra mano, la espada de la decapitación, de unas dimensiones considerables dada la altura de la figura en el conjunto de la escena.

En las tablas de la derecha se alude a los tres momentos finales de su vida: el martirio, la decapitación y sepultura, en este orden de representación de arriba abajo. La primera escena, la del martirio, representa a Santa Catalina arrodillada y desnuda en el centro de la máquina del martirio tras el momento de su destrucción, pues se aprecian algunos de los fragmentos de las ruedas rotas. Frente a ella se encuentra el rey, sentado en el trono y en actitud relajada. En la parte posterior derecha de la escena se ve a un grupo de gente cubriéndose el rostro para que los restos de las ruedas no les corten la cara, sin embargo, en la parte izquierda se ve a un grupo de ángeles que va en auxilio de Catalina. La escena central muestra la decapitación de la joven, en ella se aprecia a Santa Catalina vestida con ropa que nos hace ver la alta clase social de la joven. Ella arrodillada ante su verdugo, que se encuentra con la espada en alto. Frente a ellos está el rey con cara de alegría. Completan la escena una serie de personas que se han acercado a contemplar el momento. $Y$ finalmente, en la parte inferior encontramos a Catalina yacente en su tumba, mientras un grupo de ángeles la levantan, para que ascienda a los cielos junto a Cristo.

Para rematar la parte inferior del conjunto, Reixac nos presenta una predela con diferentes santos y santas, entre las que podemos diferencias a dos santas mártires gracias a la palma del martirio, muestra de su sufrimiento.

En la provincia de Castellón encontramos también al Maestro de Altura, el cual, en sus obras nos muestra tres representaciones de la santa que estamos tratando. La primera de ellas Santa Catalina fue realizada hacia 1450 (Fig. 4). Hasta nuestros días ha llegado esta tabla, que nos hace pensar que sería una parte de un retablo. En ella el pintor nos muestra un retrato de Santa Catalina. La figura de la santa destaca sobre el fondo neutro con el que el Maestro de Altura nos presenta el cuadro. En una escena donde se juega con los tonos tierra, podemos apreciar a Santa Catalina erguida, como princesa real. El Maestro de Altura, la representa con algunos de sus atributos más representativos, como son la rueda, en este caso representada en su totalidad, en la que podemos apreciar claramente las cuchillas; la corona de princesa, a sus pies vemos al emperador, derrotado por la santa y la espada de la decapitación, un arma grande, de guerrero, que Santa Catalina contempla con tranquilidad.

De este mismo autor se conserva otra tabla, más pequeña que la anterior y con la escenificación de otro pasaje de la vida de Santa Catalina, 
en esta ocasión el martirio. Según Ximo Company (1990) estas dos tablas formarían parte de un mismo retablo que nos narraba la historia de Santa Catalina. En la tabla del Martirio de Santa Catalina se muestra el momento en el que se pone fin a su vida. La joven arrodillada delante de su verdugo reza, mientras este está preparado para hundir la espada en su cuello. Completan la escena el emperador, vestido con ropa más elegante que el resto de espectadores y con una espada en un lateral que nos muestra que lo que él dictamina es la ley, éste observa expectante la estocada junto con un grupo de sabios y filósofos agrupados para contemplar la escena.

Finalmente, y atribuido también al Maestro de Altura, se han localizado unos Compartimentos de retablo con predelas de Santas, 14601470. En ellas aparecen representadas cuatro santas con sus atributos más característicos: Santa Catalina de Alejandría con la rueda y la espada, Santa Lucía portando unos ojos en una bandeja, Santa Bárbara llevando una pequeña torre con tres ventanas y Santa Águeda portando unos pechos sobre una bandeja (Fig. 5).

Si analizamos la figura de Santa Catalina de forma individual se puede apreciar la similitud estilística con la retratada en 1450 por el mismo pintor, sin embargo, en esta representación el Maestro de Altura nos la muestra sin la figura del emperador bajo sus pies, aun así, destacan los atributos de la corona, la rueda y la espada, esta última al igual que en la representación de la década anterior es excesivamente grande para que fuera utilizada por una mujer. Y en ambas representaciones el Maestro de Altura las pinta de rojo, el color de la sangre.

Por otro lado, si nos fijamos en el conjunto de las cuatro santas, se aprecia con claridad que Santa Catalina es la única a la que no se la representa con la palma del martirio. Esta encarnación de la santa nos podría llevar a pensar que la palma del martirio no es uno de los atributos a los que más importancia se les dio en el siglo XV a la hora de retratala. Cierto es que es una de las cuatro santas capitales de la cristiandad y que podría ser este un modo de resaltar esa importancia. Pero esta teoría queda descartada dado que en la parte inferior de la tabla está representada Santa Bárbara que es junto con Santa Catalina, Santa Margarita y Santa Dorotea una de las Quatuor Virgines Capitales.

Al lado de Altura, en Segorbe, encontramos otro retablo en el que la figura de Santa Catalina de Alejandría adquiere un lugar de importancia dentro del conjunto. Estamos hablando del Retablo de las Almas y Misas de San Gregorio, atribuido al Maestro de Perea. En la obra de este artista podemos apreciar la transición del estilo hispano-flamenco hacia la primera toma de contacto con el renacimiento. En el estilo de dicho pintor se aprecia claramente la influencia de Reixach y por consiguiente la de Jacomart, sobre todo, en la representación de figuras femeninas. El presente retablo está constituido por tres tablas y una predela, rodeando las tablas encontramos una serie de compartimentos en los que se localizan a diferentes santos de la cristiandad. Destacar de este retablo la tabla de la izquierda donde se representa a Santa Catalina de Alejandría. En ella la figura erguida de la joven se sobrepone sobre un fondo dorado. 
La muchacha aparece coronada y cubierta por una capa en tonos dorados y naranjas, la cual queda abierta exclusivamente por la zona del vientre por donde la joven muestra sus manos, en las que porta la palma del martirio en una y la espada en la otra. En un lateral se aprecia una rueda dentada, de tamaño reducido en comparación con las representadas en tablas anteriores. A sus pies el emperador con la boca abierta y descansando sobre ella la punta de la espada. Es en el rostro de la joven, donde podemos apreciar el estilo renacentista que se mencionaba con anterioridad, pues este muestra una belleza y unos rasgos parecidos a los representados por los artistas italianos.

A finales del siglo XV ya encontramos en el mundo de la pintura valenciana las formas italianizantes, pero no es hasta principios del XVI cuando realmente se hace un gran eco de ellas. Dos fueron los pintores que introdujeron estas nuevas forma en el Reino, Fernando Yánez de la Almedina y Fernando de Llanos.

Como se puede comprobar con las diferentes obras analizadas, el atributo de la rueda y el de la espada destacan sobre todos los demás. La espada toma en la representación de la joven un papel significativo, dejando en muchas ocasiones a la rueda como elemento secundario. Este hecho es de relevancia dado que la rueda debería ser su elemento principal, ya que, cuando se la representa en las predelas es el atributo que se le destaca junto con la palma del martirio, para hacer alusión a su condición de mártir. Sin embargo, cuando se la representa como a un personaje principal, en la pintura valenciana del siglo XV, la espada adquiere la mayor importancia. Este dato, lo considero de relevancia ya que la espada hace alusión a la decapitación y Santa Catalina no fue la única mártir femenina decapitada, como ejemplo de ello tenemos a Santa Bárbara, a la cual hemos visto en alguno de los retablos. En las representaciones vistas a lo largo del trabajo podemos apreciar como Santa Bárbara es representada con la palma del martirio y la torre con las tres ventanas, atributos característicos de la joven. Santa Bárbara al igual que Santa Catalina fue retratada en diversas ocasiones en el periodo que estamos tratando, como muestra de ello tomaremos la obra de Gonçal Peris titulada Retablo de Santa Bárbara, que hoy en día se encuentra en el Museo Nacional de Arte de Cataluña, aunque proviene de la iglesia de Puertomingalvo (Fig.6). Este retablo tiene como figura central a Santa Bárbara portando sus atributos característicos, la palma y la torre, lugar donde su padre la encerró para que ningún joven pudiera apreciar su belleza, ésta última destaca sobre la palma. Sobre la imagen encontramos una Crucifixión y la parte inferior del retablo está compuesto por una predela. A los laterales de la tabla central, donde aparece la figura de Santa Bárbara a modo de retrato, encontramos diferentes escenas de lo que fue su vida, entre las que se pueden ver: el momento de su martirio y la decapitación.

Como se puede comprobar por su leyenda y por algunos de los retablos que han llegado a nuestro tiempo, esta santa también fue decapitada y sin embargo, la espada no aparece representada en las 
imágenes tratadas para este trabajo. La muestra más representativa de que la espada es un elemento importante para Santa Catalina la encontramos en los compartimentos de un retablo con figuras de Santas atribuido al Maestro de Altura (Fig.5). En él cómo hemos mencionado anteriormente se ven representadas a cuatro mártires: Santa Catalina y Santa Bárbara, en una tabla y a Santa Lucía y Santa Águeda, en la otra. Las tres últimas santas mencionadas, aparecen representadas de forma muy similar con la palma del martirio en la mano exterior del cuadro y su atributo representativo en la interior. Sin embargo, Santa Catalina, nos muestra en la mano exterior la espada y en la interior la rueda, con esto el artista nos demuestra que le da más importancia a la espada que a la palma, por consiguiente en esta santa es más importante que fue decapitada que qué es mártir. Ha esto cabe sumarle que si nos fijamos en la forma de vestir de las cuatro jóvenes, apreciamos que la ropa de Santa Catalina es más lujosa que la de las otras tres mártires y ella está coronada de forma diferente a las otras, hasta la caída de su cabello la diferencia de las demás. Esto nos hace pensar que el artista la quería dotar de una majestuosidad que no tienen las demás. Cierto es que de las cuatro santas representadas es la única que tiene ascendencia real, pero las otras mártires a excepción de Santa Lucía provienen de familias de la alta nobleza.

La comparación con otras santas nos hace corroborar la teoría de que la espada fue un elemento importante a la hora de representar a Santa Catalina como figura aislada, a pesar de que en las predelas aparece en la mayoría de ocasiones con la rueda dentada.

\section{Conclusiones}

En un periodo de conflictos tanto en política interna como externa, la pintura se ve financiada por las elites valencianas del momento. Estas obras destacan en su gran mayoría por representar escenas religiosas. En una sociedad analfabeta la pintura era la mejor forma de explicar los personajes bíblicos, entre los que encontramos la vida de los santos, personajes reales y legendarios que sirvieron de modelo de conducta para los feligreses. Gracias a estas leyendas y a la importancia que la Iglesia le dio, hoy en día encontramos grandes conjuntos monumentales donde se narraron las historias de cada uno de ellos. Dentro de los santos encontramos un grupo denominado mártires, estos llevaron hasta las últimas consecuencias su creencia en Dios llegando a superar diferentes tipos de tortura por defender aquello en lo que creían. Es dentro de este grupo donde encontramos a Santa Catalina de Alejandría.

El estudio de las diferentes imágenes nos demuestra que los atributos con los que Santa Catalina de Alejandría fue representada en el periodo comprendido entre 1400 y 1500 no varían, todo y que este momento histórico abarcó diferentes corrientes artísticas. Cierto es que de todos los atributos con los que la joven fue representada: la rueda, la espada, la corona, el libro, la palma, el anillo o la cabeza del emperador bajo sus pies, 
hay unos que predominan sobre los otros. La rueda y la espada son a los que más importancia se les ha dado en las diferentes obras que se han analizado, sobre todo, a la espada que por sus dimensiones y posición ha adquirido importancia respecto al resto. El significado originario del atributo de la espada es que la o el portador de la misma fue decapitado, aunque dada la importancia que tiene en esta santa hace pensar que la espada podría tener otro significado, ya que como se ha comprobado Santa Bárbara también fue decapitada y en las imágenes utilizadas para dicho trabajo no se la representa con ella.

\section{Bibliografia}

AAVV (1984): Obras completas de San Agustín de Hipona. XXV. Sermones (5ㅇ), 273-338. Sermones sobre los mártires, Biblioteca de autores cristianos, Madrid.

AAVV (2001): La Luz de las Imágenes. Segorbe, Generalitat Valenciana, Valencia.

CHECA Cremades, F.; GARCÍA Felguera, M.S.; MORAN, Torina, M. (1980): Guía para el estudio de la historia del arte, Cátedra, Madrid.

COMPANY, X. (1990): La pintura hispanoflamenca, Edicions Alfons en Magnanim, Valencia.

-(2006): La retablística en el área valenciana. Gótico y renacimiento, siglos XIV, XV y XVI. Los retablos: técnicas, materiales y procedimientos, España, pp.3.

FURIÓ, A. (2001): Història del País Valencia, Biblioteca d'estudis i investigacions 3 i 4, Valencia.

GIORGI, R. (2005): Santos, Los diccionarios del arte, Electa, Barcelona.

REAU, L. (1955-1958): Iconographie de l'art Chrétien. Iconographie des saints, vol. 3, Presses Universitaires de France, París.

VORÁGINE, S. (1982). La leyenda dorada. Tomo 1 y 2, Alianza forma, Madrid.

ZURIAGA, V.F.. (2012). "El dolor como triunfo. Sacrificio, tortura y liberación en las mártires cristianas» en Dossiers Feministes, 16, Publicaciones de la Universitat Jaume I, Castellón de la Plana, pp. 157-177 

XV
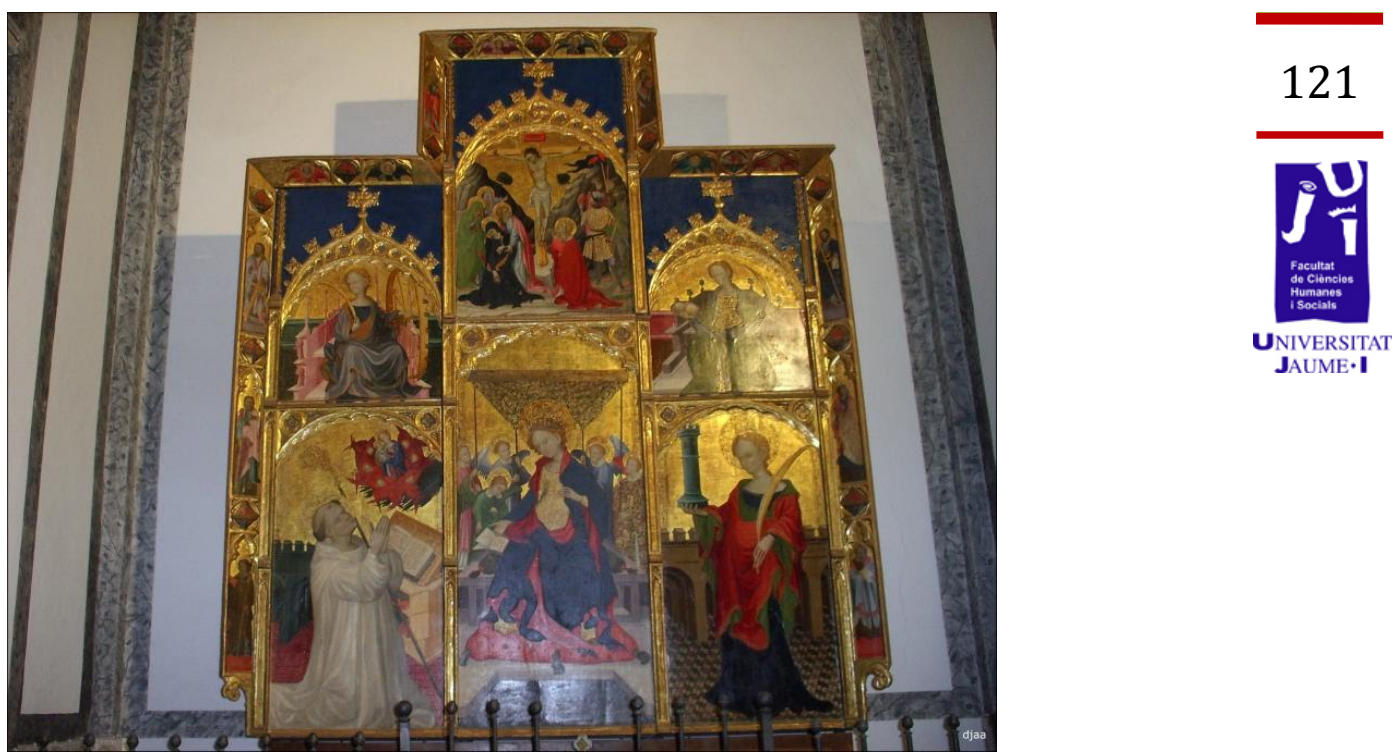

Fig. 1. Jaume Mateu y Antoni Peris. Compartimentos del retablo de la Virgen de la Esperanza: Visión mística de San Bernardo y Calvario. h. 1412-1420. Ermita de la Virgen de la Esperanza Parroquia de Nuestra Señora de la Asunción de Albocàsser. Castellón. Imagen extraída de: AAVV (2001): La Luz de las Imágenes. Segorbe, Generalitat Valenciana, Valencia.

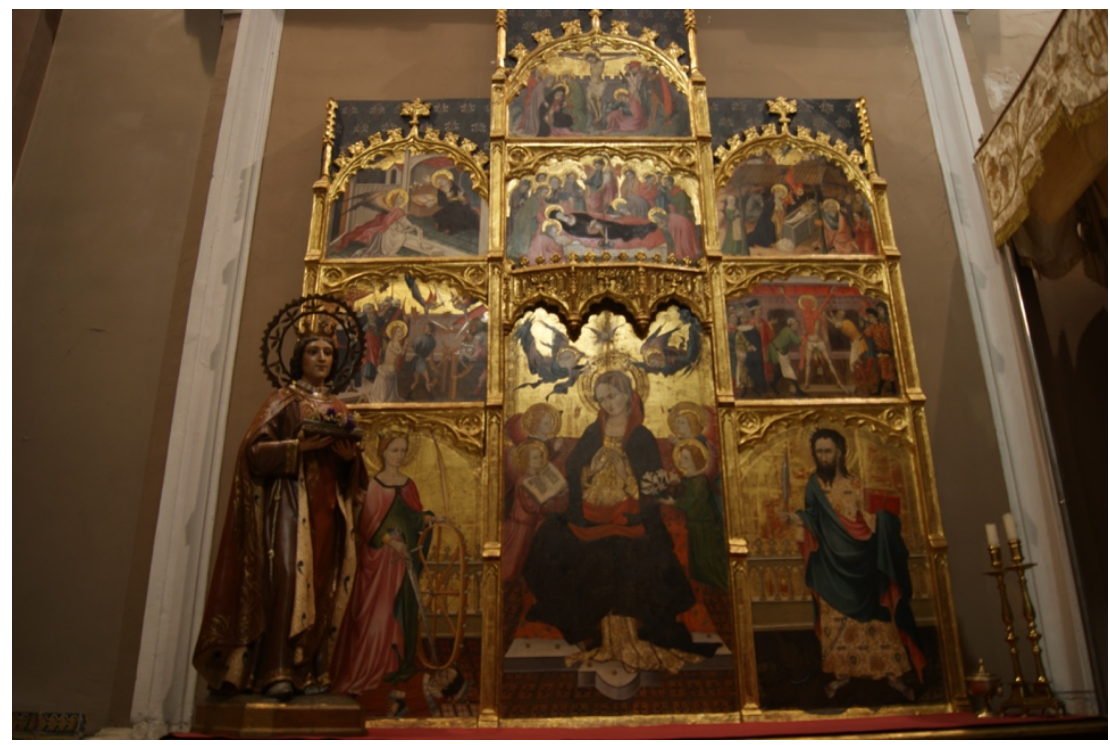

Fig. 2. Antoni Peris y Maestro de Ollería. Retablo de la Virgen de la Esperanza. Iglesia Arciprestal de la Asunción de Nuestra Señora, S.XV. Pego, Alicante. Imagen pròpia. 

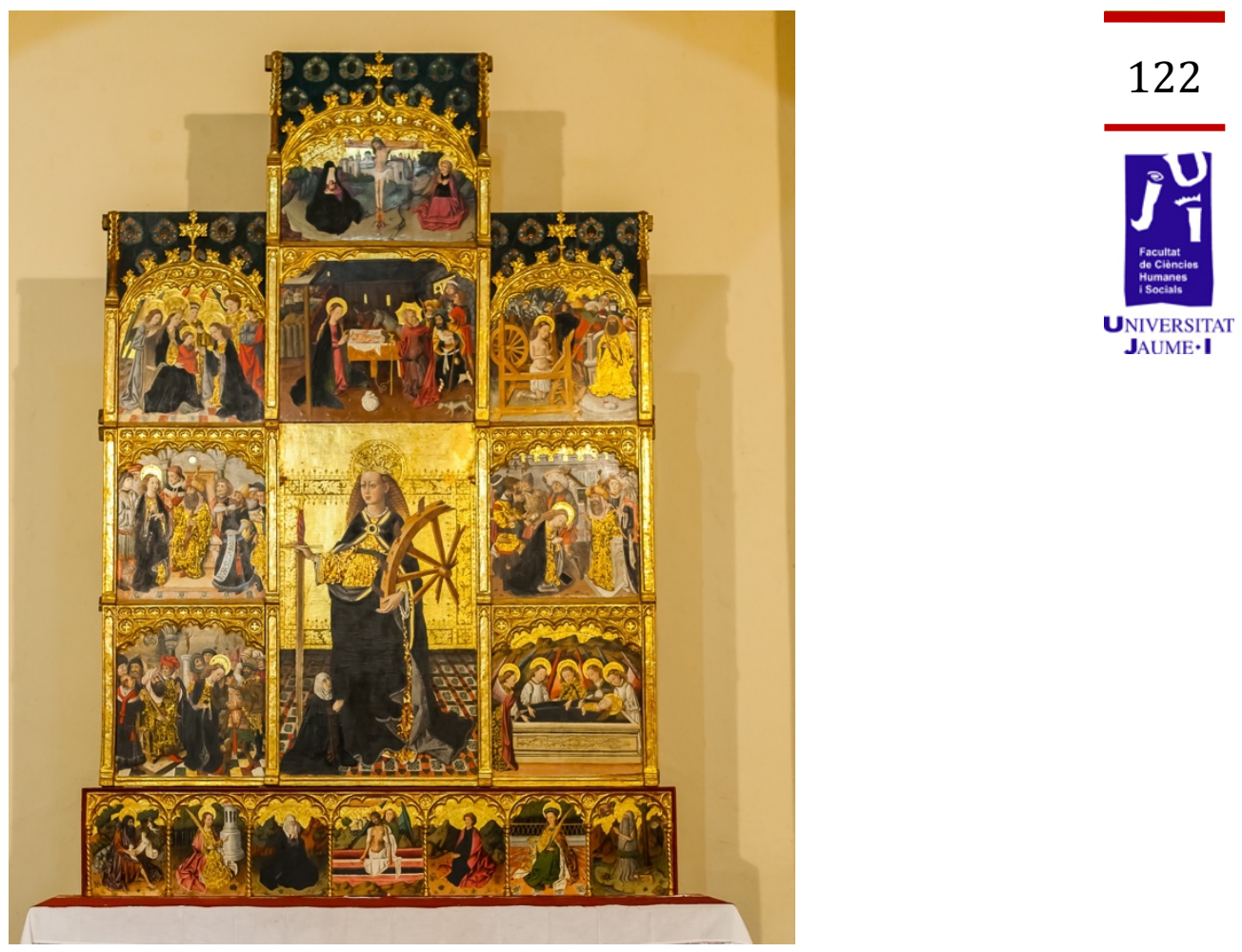

Fig. 3. Juan Reixach. Retablo de Santa Catalina Mártir. 1448. Iglesia Parroquial de Villahermosa del Río, Castellón. Imagen propia.

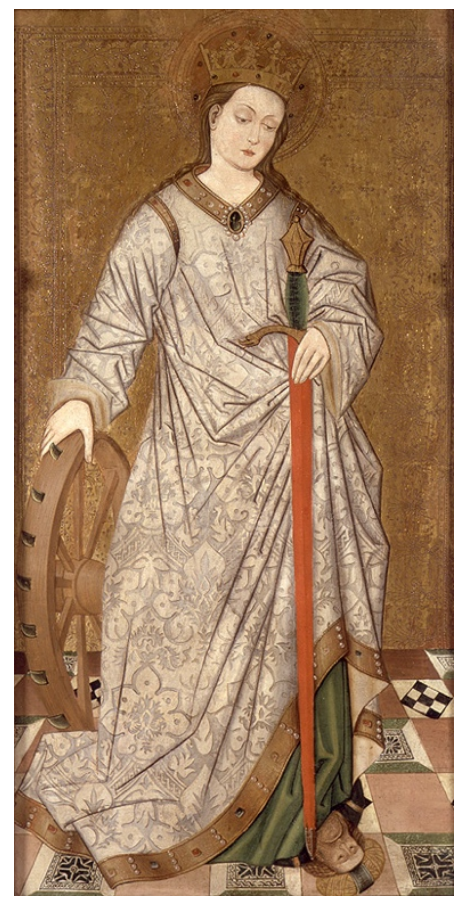

Fig. 4. Maestro de Altura. Santa Catalina. h1450. Museo de Bellas Artes de Valencia, Valencia. Imagen extraída de: http://www.cult.gva.es/mbav/data/191.jpg 
Nuria Mampel Muñoz. Iconografía de Santa Catalina de Alejandría en la pintura valenciana del siglo XV

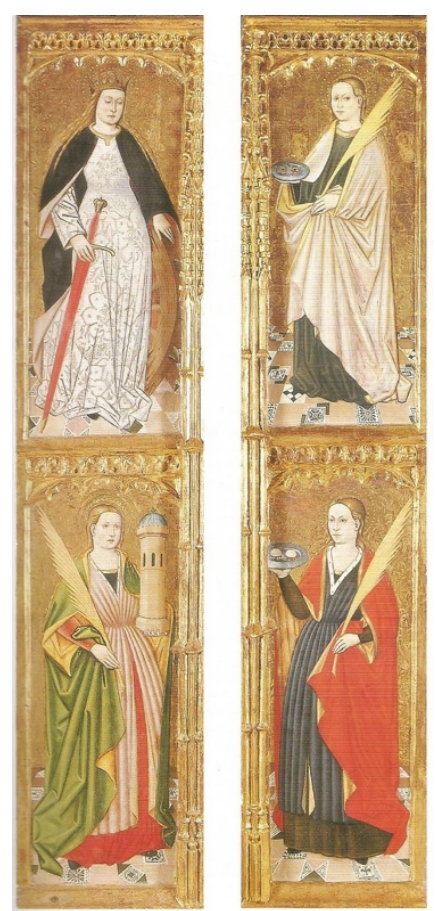

123

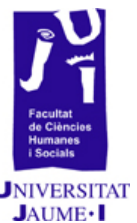

Fig. 5. Maestro de Altura. Compartimentos de un retablo con figuras de Santas. h. 1460-1470 Iglesia Parroquial de San Miguel Arcángel de Altura, Castellón. Imagen extraída de: AAVV (2001): La Luz de las Imágenes. Segorbe, Generalitat Valenciana, Valencia.

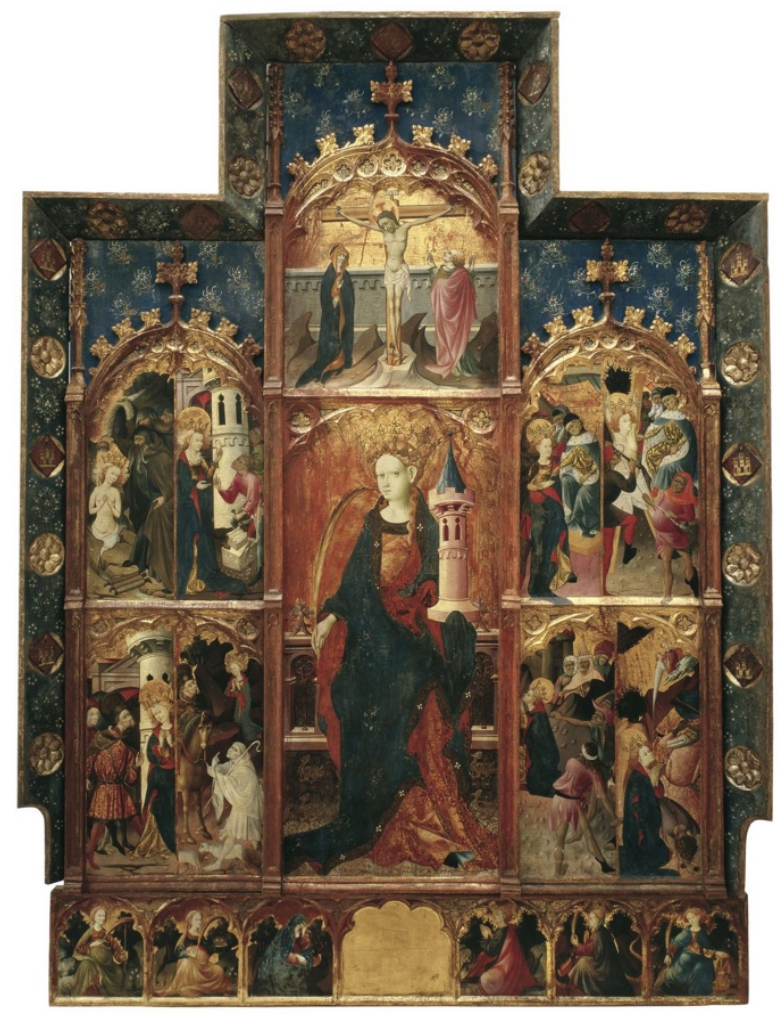

Fig. 6. Retablo de Santa Bárbara. 1410-1425. Museo Nacional de Arte de Cataluña, Barcelona. Imagen extraída de: http://www.museunacional.cat/ca/colleccio/retaule-de-santa-barbara/goncal-perissarria/035672-cjt. 